This is an electronic reprint of the original article. This reprint may differ from the original in pagination and typographic detail.

Author(s): Neuvonen, Antti; Földes, Tamás; Madarász, Ádám; Pápai, Imre; Pihko, Petri

Title: $\quad$ Organocatalysts Fold to Generate an Active Site Pocket for the Mannich Reaction

Year: $\quad 2017$

Version:

Please cite the original version:

Neuvonen, A., Földes, T., Madarász, Á., Pápai, I., \& Pihko, P. (2017). Organocatalysts Fold to Generate an Active Site Pocket for the Mannich Reaction. ACS Catalysis, 7(5), 3284-3294. https://doi.org/10.1021/acscatal.7b00336

All material supplied via JYX is protected by copyright and other intellectual property rights, and duplication or sale of all or part of any of the repository collections is not permitted, except that material may be duplicated by you for your research use or educational purposes in electronic or print form. You must obtain permission for any other use. Electronic or print copies may not be offered, whether for sale or otherwise to anyone who is not an authorised user. 


\title{
Organocatalysts Fold to Generate an Active Site Pocket for the Mannich Reaction
}

\author{
Antti J. Neuvonen, ${ }^{\dagger}$ Tamás Földes, ${ }^{\ddagger}$ Ádám Madarász, ${ }^{\ddagger}$ Imre Pápai, ${ }^{*, \ddagger}$ and Petri M. Pihko ${ }^{*, \dagger}$ \\ ${ }^{\dagger}$ Department of Chemistry and NanoScience Center, University of Jyväskylä, FI-40014 JYU, Finland, and ${ }^{\ddagger}$ Research Center for Natu- \\ ral Sciences, Hungarian Academy of Sciences, Magyar tudósok körútja 2, H-1117, Budapest, Hungary
}

\begin{abstract}
Catalysts containing urea, thiourea and tertiary amine groups fold into a three-dimensional organized structure in solution both in the absence as well as in the presence of substrates or substrate analogues, as indicated by solution NMR and computational studies. These foldamer catalysts promote Mannich reactions with both aliphatic and aromatic imines and malonate esters. Hammett plot and secondary kinetic isotope effects provide evidence for the $\mathrm{C}$ - $\mathrm{C}$ bond forming event as the turnover-limiting step of the Mannich reaction. Computational studies suggest two viable pathways for the $\mathrm{C}$ - $\mathrm{C}$ bond formation step, differing in the activation modes of the malonate and imine substrates. The results show that the foldamer catalysts may promote $\mathrm{C}-\mathrm{C}$ bond formation with an aliphatic substrate bearing a cyclohexyl group by enhanced binding of the substrates by dispersion interactions, but these interactions are largely absent with a simpler catalyst. Additional control experiments demonstrate the ability of simple thiourea catalysts to promote competing side reactions with aliphatic substrates, such as reversible covalent binding of the thiourea sulfur to the imine which deactivates the catalyst, and imine-to-enamine isomerization reactions. In foldamer catalysts, the nucleophilicity of sulfur is reduced, which prevents catalyst deactivation. The results indicate that the improved catalytic performance of foldamer catalysts in Mannich reactions may not be due to cooperative effects of intramolecular hydrogen bonds, but simply due to the presence of the folded structure that provides an active site pocket, accommodating the substrate and at the same time impeding undesirable side reactions. KEYWORDS: organocatalysis, bifunctional, cooperativity, mechanism, kinetics, computations, Mannich reaction
\end{abstract}

\section{INTRODUCTION}

Enzymes bind their substrates into a characteristic active site cleft that contributes to binding and the remarkable degree of selectivity obtained in enzymatic catalysis. ${ }^{1}$ In contrast, many organocatalysts are small molecules that do not appear to possess any folded active site cleft, yet they are often able to exhibit remarkable degrees of selectivity as well. ${ }^{2}$

We have previously described a family of urea-thiourea-tertiary amine catalysts (1a-c in Scheme 1) that appear to fold into a conformation with an active site pocket. These catalysts promote highly enantioselective Mannich reactions of malonates and $\beta$-keto esters with aromatic and aliphatic imines (Scheme 1). ${ }^{3}$ In contrast to the prototype small molecule bifunctional catalyst, Takemoto's thiourea-tertiary amine catalysts $(2 a),{ }^{4}$ these new catalysts readily accepted both aliphatic and aromatic imines as electrophiles in the Mannich reaction. The design of these catalysts was sparked by the seminal work of Smith who showed that intramolecular hydrogen bonds between urea and thiourea groups lead to enhanced reactivity. ${ }^{5}$ An alternative explanation for the higher activity of our catalysts is that the intramolecular hydrogen bond generates a folded structure and an active site cleft in the catalyst. Such folding is not possible with catalyst 2 a.

Herein we show that these catalysts indeed form a well-defined folded structure in solution, even in the presence of substrates or substrate analogues. Furthermore, the most likely reason for the superiority of the new catalyst family is that the active site pocket, generated upon folding of the catalyst, allows additional stabilizing interactions with the substrates and facilitates the turnoverdetermining $\mathrm{C}-\mathrm{C}$ bond formation step.

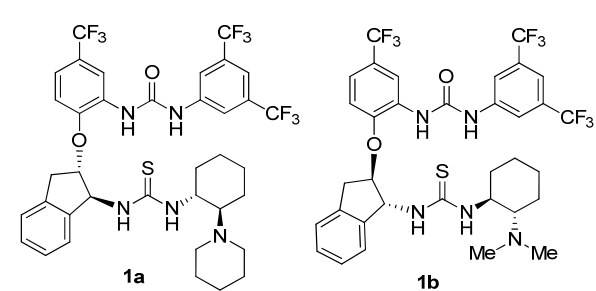

1b

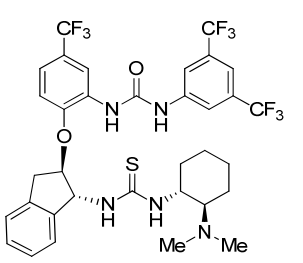<smiles></smiles>

1c
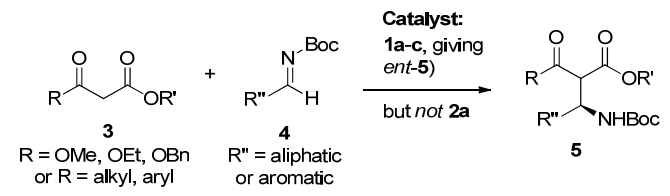

Scheme 1 . Catalysts $1 \mathrm{a}-1 \mathrm{c}$ and $2 \mathrm{a}$ and their contrasting reactivity

The dual activation modes of tertiary amine-thiourea bifunctional organocatalysts have previously been studied using both computational and experimental methods. ${ }^{6}$ In addition, the H-bond donor ability of thioureas and other hydrogen-bonding catalysts have been studied by colorimetry by Kozlowski. ${ }^{7}$ However, the folded, more complex nature of catalysts 1a-c suggests that mechanistic lessons learned in previous studies should be complemented for 
these catalysts. To enable a more rational design of future catalysts, and to expand the substrate scope, we undertook a combined experimental and computational mechanistic study of these new catalysts.

\section{RESULTS}

Conformational Analysis of Catalyst 1a in Solution. We had previously established that catalyst $1 \mathrm{~b}$, or its diastereomer $1 \mathrm{c}$, could fold into at least two completely different conformations with different anions (Figure 1$)^{8}$.

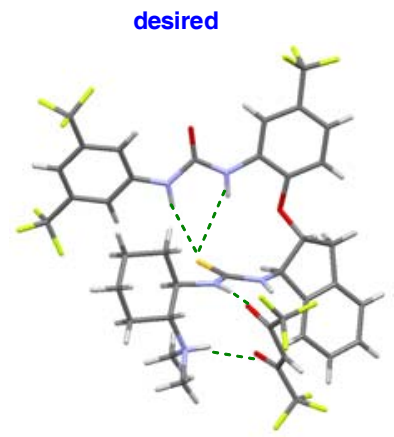

X-ray of catalyst $\mathbf{1 c} \cdot$ hfacac

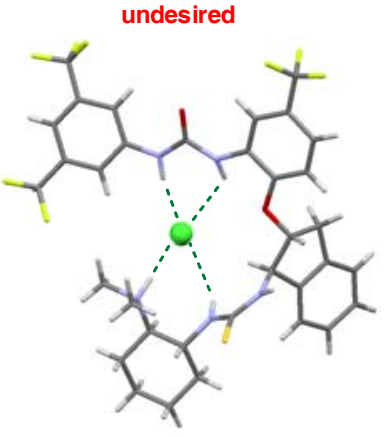

X-ray of catalyst $1 \mathrm{c} \cdot \mathrm{HCl}$
Figure 1. Comparison of X-ray structures of two different salts of catalyst 1c, showing that at least two possible folds are readily accessible.

The first conformation, corresponding to an intramolecularly hydrogen bonded structure, is observed when the catalyst forms a salt with a malonate surrogate, hexafluoroacetylacetonate ( $h f a c a c$ ). The hfacac salt might be viewed as an analogue of the corresponding catalyst-malonate ion pair that likely forms in the Mannich reaction. The second conformation was observed in the $\mathrm{HCl}$ salt of 1c. ${ }^{3 a}$ These results, however, were obtained in the solid state.

To elucidate the major populated conformations in solution, a benzene- $d 6$ solution of catalyst 1 a was studied by ${ }^{1} \mathrm{H}$ NMR measurements. NOESY cross peaks in the free catalyst $1 \mathrm{a}$ in benzene (Figure 2) are consistent with the obtained crystal structure of the folded urea complex $\left((1 \mathrm{a})_{2} \cdot\right.$ urea $\left.\cdot \mathrm{MeCN}\right)$ of the catalyst (see the Supporting Information). Importantly, the same characteristic NOESY cross peaks were also observed in the spectrum of the hfacac salt of 1a in benzene. These NMR experiments thus established that the fold of the catalyst remains similar in both free state as well as the catalytically relevant ion pair complex (assuming that the fold remains similar with the malonate salt and the hfacac salt). The presence of several close contacts in the structure indicates that the fold is tight, and the piperidine ring $\mathrm{A}$ as well as the indane (CD) and one of the aryl rings (E) can form the walls of a possible catalytic pocket (Figure 2).

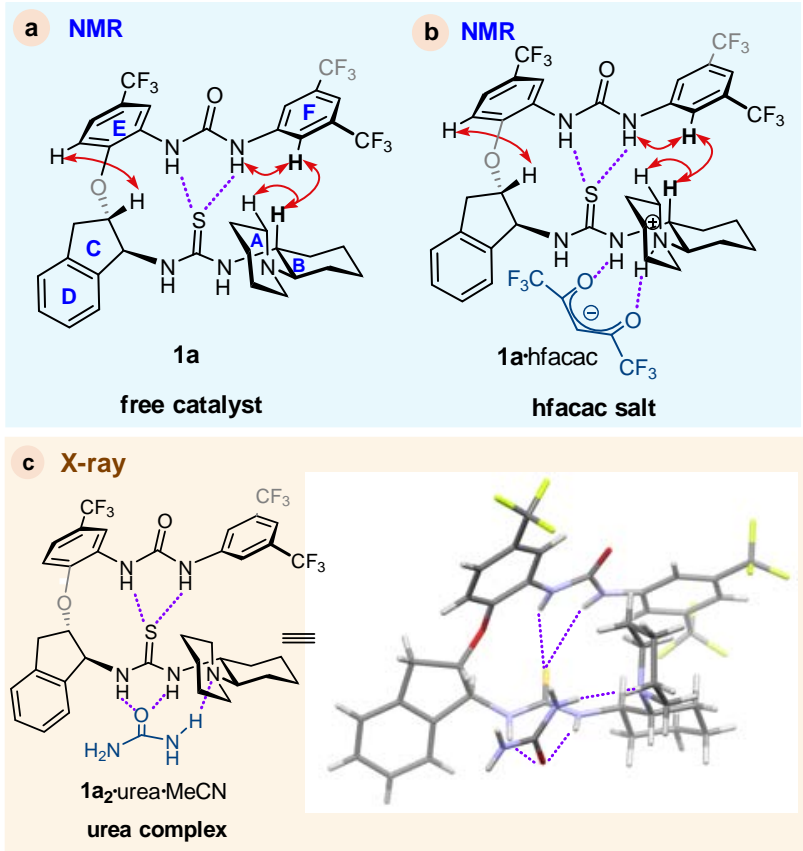

Figure 2. a) Structurally diagnostic $2 \mathrm{D}$ nOe cross peaks of $1 \mathrm{a}$ and b) $1 \mathrm{a} \cdot \mathrm{hfacac}$ in benzene- $d 6$ at $30^{\circ} \mathrm{C}$. c) X-ray structure of 1a complexed with urea and $\mathrm{MeCN}$ (MeCN molecule omitted for clarity).

Our computational analysis ${ }^{9}$ provides further support for the preference of the folded structure of catalyst $1 \mathrm{a}$. We find that the most stable form of 1a features an asymmetric double hydrogen bonding pattern between the urea and thiourea moieties with an additional intramolecular hydrogen bond formed between the tertiary amine and the adjacent $\mathrm{NH}$ group (see Figure 3). The unfolded structures (i.e. those without N-H...S hydrogen bonds) are all predicted to be at least $8 \mathrm{kcal} / \mathrm{mol}$ less stable than the most favored conformer. ${ }^{10}$

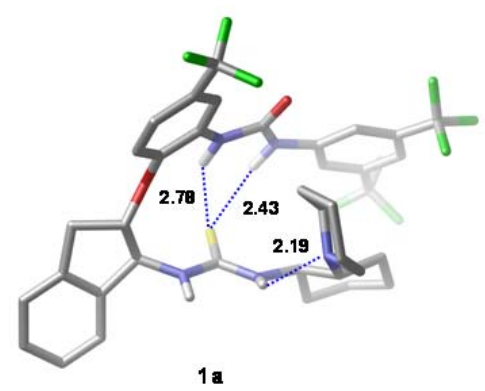

Figure 3. The most stable conformer of catalyst $1 \mathrm{a}$ as predicted by DFT calculations. Internal hydrogen bonds are indicated by blue dotted lines (related distances are given in $\AA$ ). Hydrogen atoms are omitted for clarity, except those of $\mathrm{NH}$ groups.

Catalyst-substrate binary complexes. In the folded structure of catalyst 1a, the thiourea $\mathrm{NH}$ groups are easily accessible by the substrate molecules, so the formation of binary complexes is expected. Computations were carried out for binary 1a.substrate systems relevant to our present mechanistic studies (Scheme 2). 
$\underbrace{\stackrel{O}{O}{ }_{\mathrm{OMe}}}_{3 a}$<smiles>[X][Y4]([H])=O</smiles><smiles>CC(C)COC(=O)/N=C/C1CCCC1</smiles>

Scheme 2. Substrates used in the computational study of binary complexation.

Dimethyl-malonate $3 \mathrm{a}$ forms a multiple $\mathrm{H}$-bonded complex with 1a as shown in Figure 4, however, the complexation is predicted to be slightly endergonic. In complex $1 \mathrm{a} \cdot 3 \mathrm{a}$, one of the $\mathrm{C}-\mathrm{H}$ bonds of the methylene group is oriented towards the basic center of the catalyst, so the malonate is structurally well prepared for deprotonation. The deprotonation occurs via a relatively low barrier (14.7 $\mathrm{kcal} / \mathrm{mol})$ and leads to an ion-pair $\left(1 \mathrm{aH}^{+} \cdot 3 \mathrm{a}^{-}\right)$lying at +4.7 $\mathrm{kcal} / \mathrm{mol}$ in free energy. ${ }^{11}$

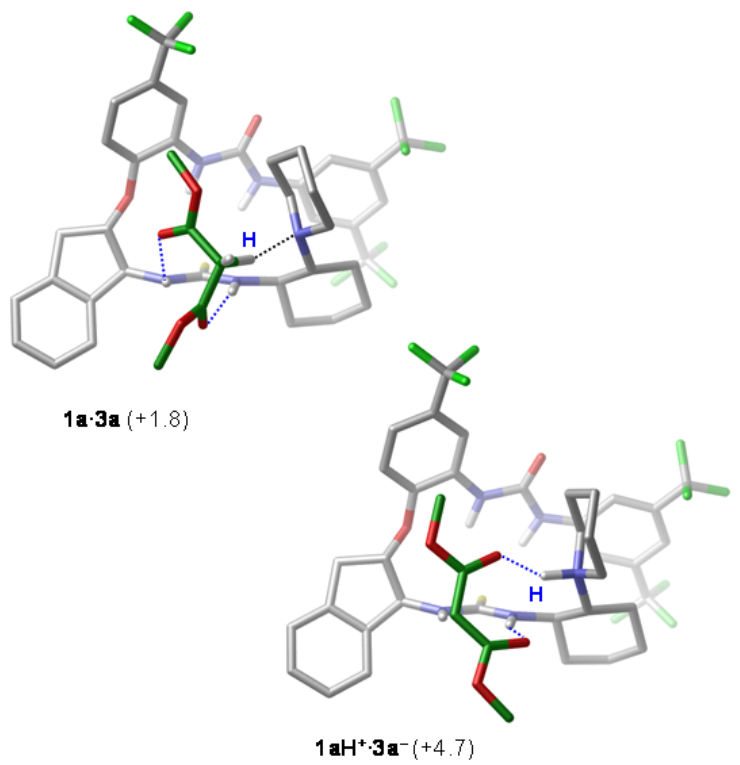

Figure 4. Binary complex 1a.3a and the ion-pair formed upon substrate deprotonation. Relative stabilities (in $\mathrm{kcal} / \mathrm{mol}$; with respect to $1 \mathrm{a}+$ 3a) are given in parenthesis. For the sake of clarity, internal H-bonds between urea and thiourea are not indicated. Most of the hydrogen atoms are not shown either (except those of $\mathrm{NH}$ groups and the $\mathrm{CH}_{2}$ of $3 \mathrm{a}$ in $\mathbf{1} \mathbf{a} \cdot \mathbf{3 a}$ ). Carbon atoms of the substrate are highlighted in dark green. Hydrogen involved in proton shift is marked with blue $\mathrm{H}$.

Various binding modes could be identified computationally for imine 4a. In the most stable form, the imine binds via its $\mathrm{N}$ atom to thiourea (see Figure 5) and this 1a.4a complex is practically isoenergetic with the dissociated state $(\mathbf{1} \mathbf{a}+\mathbf{4 a}) .{ }^{12}$ Para-substituted aromatic imines $4 \mathrm{~b}$ and $4 \mathrm{c}$ form very similar binary complexes with 1a. The predicted stabilities $(+0.3$ and $+1.9 \mathrm{kcal} / \mathrm{mol}$, respectively $)$ do not fully reflect the trend expected from the nature of the substituents, which is likely related to entropic effects. ${ }^{13}$ Analogous binary complex formed with the aliphatic imine $4 \mathrm{~d}$ is found to be notably less stable (at $+2.5 \mathrm{kcal} / \mathrm{mol})$.

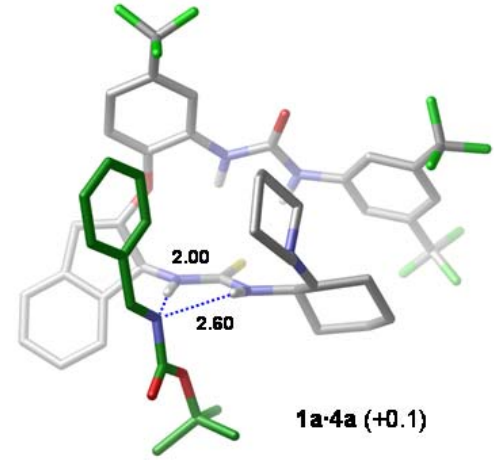

Figure 5. The most stable form of complex 1a.4a and the ion pair formed upon substrate deprotonation. Relative stability (in $\mathrm{kcal} / \mathrm{mol}$; with respect to $1 \mathrm{a}+4 \mathrm{a}$ ) is given in parenthesis.

Our attempts to identify complexes with malonate $3 \mathbf{a}$ and catalyst 1a experimentally were not productive, which is in line with the computed thermodynamics. However, with acetylacetonate (acac), a more acidic $\beta$-dicarbonyl compound, small shifts were indeed observed in NMR titration experiments (Figure 6). More pronounced shifts were observed in NMR titrations with imine $4 \mathrm{~b}$, indicating that the imine interacts with several key protons in the catalytic pocket of 1a (see Figure 6).

Shift at 5:1 ratio of acac:1a
$\mathrm{H}_{\mathrm{B} 1}+0.04 \mathrm{ppm}$
$\mathrm{H}_{\mathrm{C} 1}+0.02 \mathrm{ppm}$
$\mathrm{H}_{\mathrm{C} 2}+0.08 \mathrm{ppm}$
$\mathrm{H}_{\mathrm{N} 1}+0.32 \mathrm{ppm}$
$\mathrm{H}_{\mathrm{N} 2}+0.05 \mathrm{ppm}$
$\mathrm{H}_{\mathrm{N} 3}+0.04 \mathrm{ppm}$

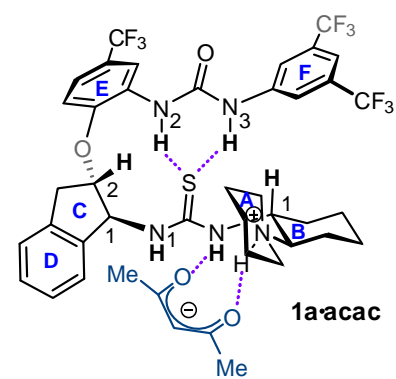

Shift at $5: 1$ ratio of $\mathbf{4 b}: \mathbf{1 a}$

$\mathrm{H}_{\mathrm{B} 1}+0.14 \mathrm{ppm}$

$\mathrm{H}_{\mathrm{C} 1}+0.11 \mathrm{ppm}$

$\mathrm{H}_{\mathrm{C} 2}+0.19 \mathrm{ppm}$

$\mathrm{H}_{\mathrm{N} 1}+\sim 1.2 \mathrm{ppm}$

$\mathrm{H}_{\mathrm{N} 2}+0.15 \mathrm{ppm}$

$\mathrm{H}_{\mathrm{N} 3}+0.11 \mathrm{ppm}$

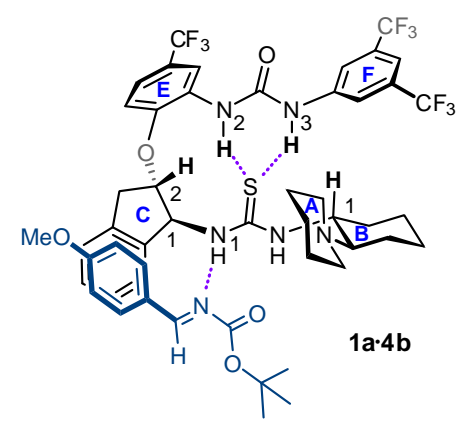

Figure 6. Summary of ${ }^{1} \mathrm{H}$ NMR shifts observed when catalyst 1a was titrated with a) acetylacetone (acac) or b) imine $4 \mathrm{~b}$.

Competition Experiments. To be able to directly compare the reactivity of aromatic and aliphatic $N$-Boc imines we conducted a series of competition experiments using two foldamer bifunctional catalysts ( $1 \mathbf{a}$ and $\mathbf{1 b}$ ), Takemoto catalyst $(2 \mathbf{a})$ and urea-Takemoto catalyst (2b) (Figure 7). In order to avoid problems associated with the imine isomerization, we selected the imine $4 \mathrm{~d}$ as the aliphatic imine since $4 \mathrm{~d}$ is less prone to isomerization side reactions than other aliphatic imines. ${ }^{14}$ As expected, arylimine $4 \mathrm{a}$ and aliphatic imine 4d exhibited clearly different reactivity when Takemoto catalyst $(2 a)$ was used. Interestingly, the urea variant of $2 a(2 b)$ 
displayed increased activity but maintained the clear reactivity difference between $\mathbf{4 a}$ and $4 \mathrm{~d}$. These graphs indicate that for aromatic imine $4 \mathrm{a}$, the foldamer structure of the bifunctional catalysts $1 \mathrm{a}$ or $1 \mathrm{~b}$ provide only a slight rate acceleration as compared to
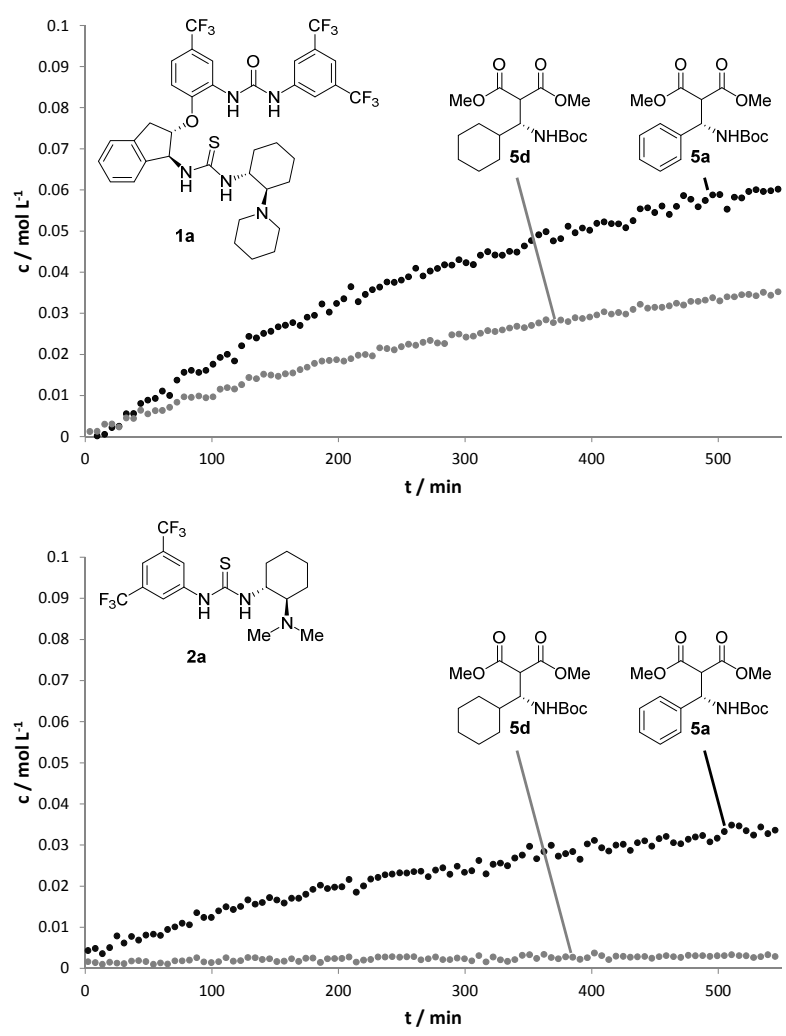

Takemoto catalyst, however, the reaction with aliphatic imine $4 \mathrm{~d}$ is catalyzed more efficiently by foldamer catalysts. Moreover, the foldamer catalyst $1 \mathrm{~b}$ gave similar initial rates for both aromatic and aliphatic imine.
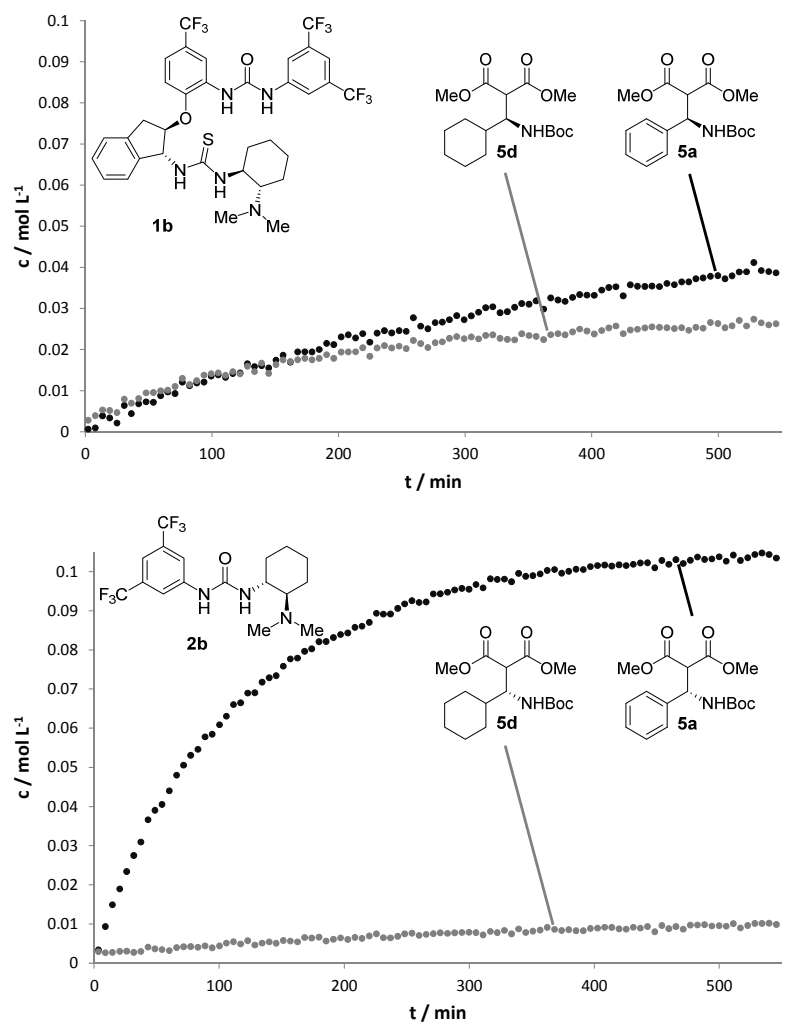

Figure 7. Mannich reaction progress curves in competition experiments between imines $4 \mathrm{a}$ and $4 \mathrm{~d}$. The product concentrations are plotted as a function of time relative to the internal standard. Reaction conditions: Catalyst $(10 \mathrm{~mol} \%),[3 \mathrm{a}]_{0}=0.2 \mathrm{M},[4 \mathrm{a}]_{0}=0.1 \mathrm{M},[4 \mathrm{~d}]_{0}=0.1 \mathrm{M},[$ dibenzyl ether $]=$ $0.2 \mathrm{M}$, benzene- $d 6$ at $30^{\circ} \mathrm{C}$. 
We had already demonstrated the superiority of catalyst 1a over $1 \mathrm{~b}$ in reactions with $\beta$-keto esters. ${ }^{3 \mathrm{~b}}$ Catalyst $1 \mathrm{a}$ was also superior to catalyst $1 \mathrm{~b}$ in preparative experiments with dimethyl malonate (Table 1). Both catalysts provide excellent isolated yields regardless of the imine used. For both imines, catalyst 1a gave better selectivity than catalyst $1 \mathrm{~b}$. Especially in the case of aromatic imine 4a the selectivity difference was significant.

Table 1. Preparative Mannich Reaction Examples with Malonate using Foldamer Catalysts $1 \mathrm{a}$ and $\mathrm{lb}$

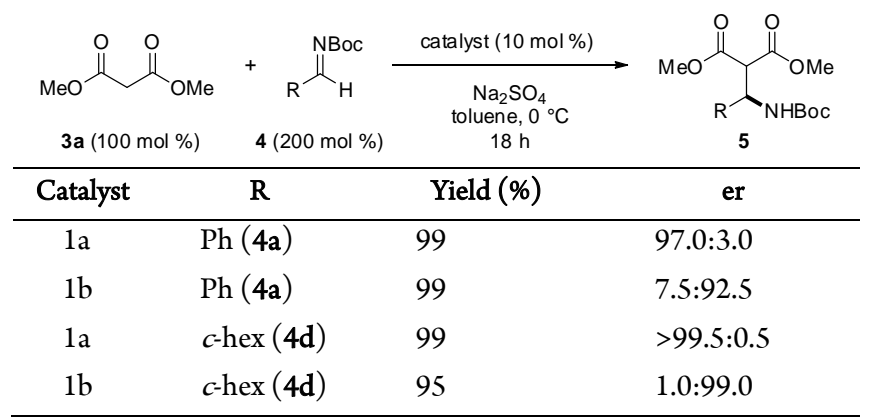

Kinetic measurements. We anticipated that a linear free-energy relationship, such as a Hammett plot (Figure 8), could clarify the rate-limiting step of the catalytic Mannich reaction. For example, if the rate is limited by the binding of the imine to the catalyst, a negative reaction constant $(\rho)$ should be obtained. In contrast, with a rate limiting $\mathrm{C}-\mathrm{C}$ bond formation, the $\rho$ value should be positive.
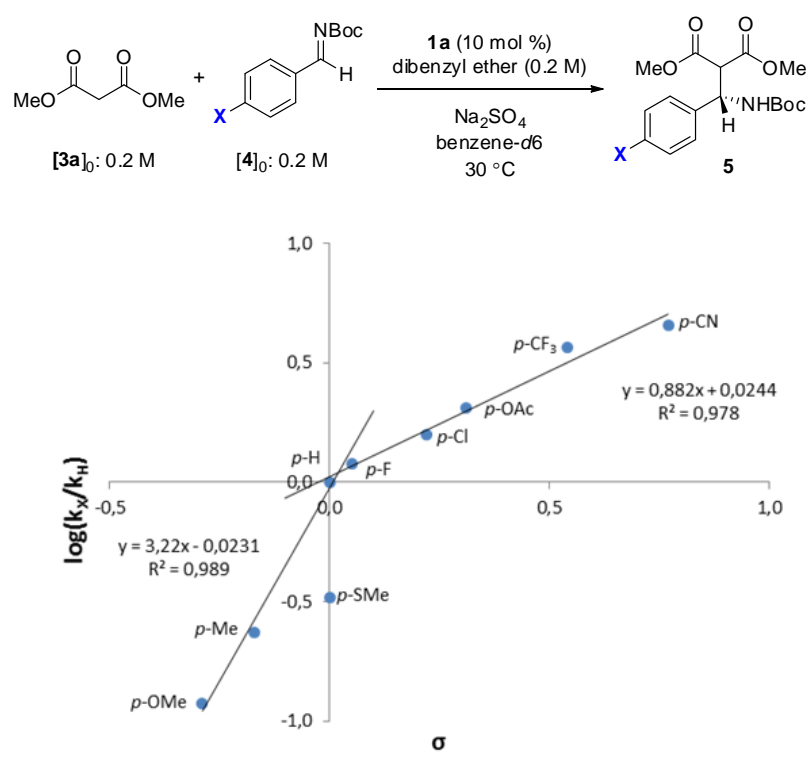

Figure 8. Hammett plot. $p$-SMe imine was omitted from the line fitting.

With 9 para-substituted imines a clear positive Hammett correlation was observed, however, there was significant deviation from linearity. ${ }^{15}$ In the Hammett plot, two subgroups were clearly distinguishable, the electron rich and the electron poor aromatic imines. For both the electron donating $\left(\rho=3.22 ; \mathrm{R}^{2}=0.989\right)$ and the electron withdrawing $\left(\rho=0.882 ; R^{2}=0.978\right)$ substituents excel- lent correlations were obtained. This relatively small deviation from linearity does not support any profound change in the reaction mechanism but instead suggests a change in the energy profile of the reaction as the electronic properties of the imine are changed. With different imines, the relative stabilities of the complexes preceding the turnover determining transition state may change, which would influence the reaction rate.

Nevertheless, the Hammett plot clearly suggests that the ratedetermining step involves a transition state with increasing electron density at the imine carbon. Thus, initial binding of the imine, or final protonation of the intermediate, are unlikely to be ratelimiting. An internal rearrangement within the catalyst structure after the $\mathrm{C}-\mathrm{C}$ bond formation event might, in theory, exhibit a positive $\rho$ value. In order to rule out this possibility, a kinetic isotope effect study with deuterium-labeled imines was carried out.

KIE measurements were conducted by ${ }^{1} \mathrm{H}$ NMR reaction monitoring by comparing the reaction rates ${ }^{16}$ with aromatic imines $4 \mathrm{a}-\mathrm{c}$ and $4 \mathrm{a}-\mathrm{c}-d 1$ with dimethyl malonate in parallel experiments (Table $2)$. In all cases, a notable inverse secondary KIE (0.90-0.93) was observed. These KIE's are indicative of a change in the bonding environment (hybridization) of the imine carbon in the ratedetermining step. Together with the Hammett plot data, these experiments strongly indicate that the $\mathrm{C}-\mathrm{C}$ bond formation is ratedetermining. An alternative rationalization for the KIEs, an inverse $2^{\circ}$ equilibrium isotope effect ${ }^{17}$ arising from the binding event of the imine, is not compatible with the results of the Hammett plot, which indicates that the rate-determining step involves an increase in the electron density of the imine carbon.

Table 2. Kinetic isotope effect measurements

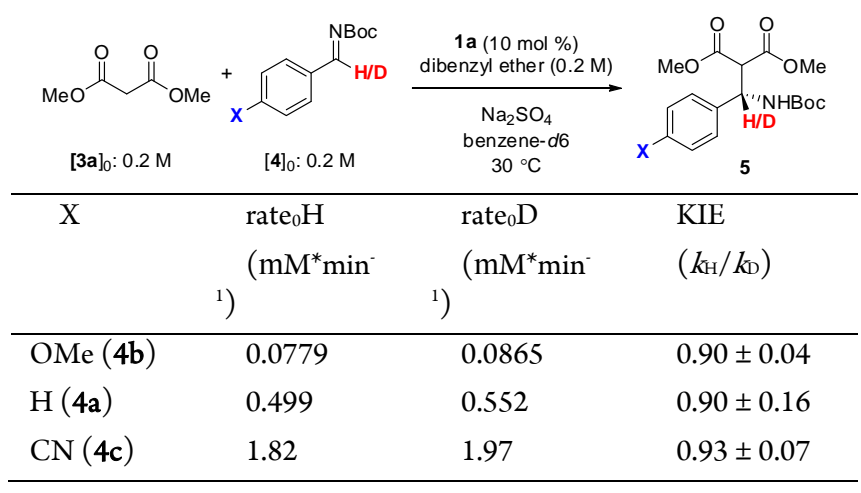

Further support for the $\mathrm{C}-\mathrm{C}$ bond formation step as the ratedetermining step could be obtained from a cross-over experiment with the Mannich reaction product $5 \mathrm{a}(0.2 \mathrm{M})$ and imine $4 \mathrm{c}(0.2$ $\mathrm{M})$ in the presence of $10 \mathrm{~mol} \%$ catalyst $1 \mathrm{a}$. In this experiment, no cross-over product was observed after $24 \mathrm{~h}$, indicating that the $\mathrm{C}-\mathrm{C}$ bond formation step is essentially irreversible.

\section{Inhibition and Complexation Experiments.}

To clarify the importance of catalyst complexation with imines we performed a kinetic experiment with $p$-CN benzaldimine (4c) and substoichiometric amount of $p$-OMe benzaldimine $(4 \mathbf{b})$ as a potent inhibitor (Scheme 3a). As the rate difference of these imines in Mannich reaction is over 20 -fold, $4 \mathrm{~b}$ can be considered purely as an inhibitor. The presence of $50 \mathrm{~mol} \%$ of $4 \mathrm{~b}$ retarded the Mannich 
reaction between $p$ - $\mathrm{CN}$ benzaldimine (4c) and dimethyl malonate by a factor of 1.88 . This inhibitory effect might result from a change in the turnover-determining intermediate (TDI) of the reaction. ${ }^{18}$ With electron-rich imine, such as $4 \mathrm{~b}$, the complex with the catalyst could become the TDI.

In addition, $4 \mathrm{~b}(50 \mathrm{~mol} \%)$ inhibited the Mannich reaction of $4 \mathrm{a}$ by a factor of 2.91 (Scheme 3b). Although in this case the reactivity difference of the imines is only 8 -fold, the Mannich reaction rate of $4 \mathrm{~b}$ was found to be negligible. These results further support the notion that competitive substrates retard the reaction by lowering the concentration of the productive complex, even if the interactions are weak (as evidenced by the NMR titration experiments).

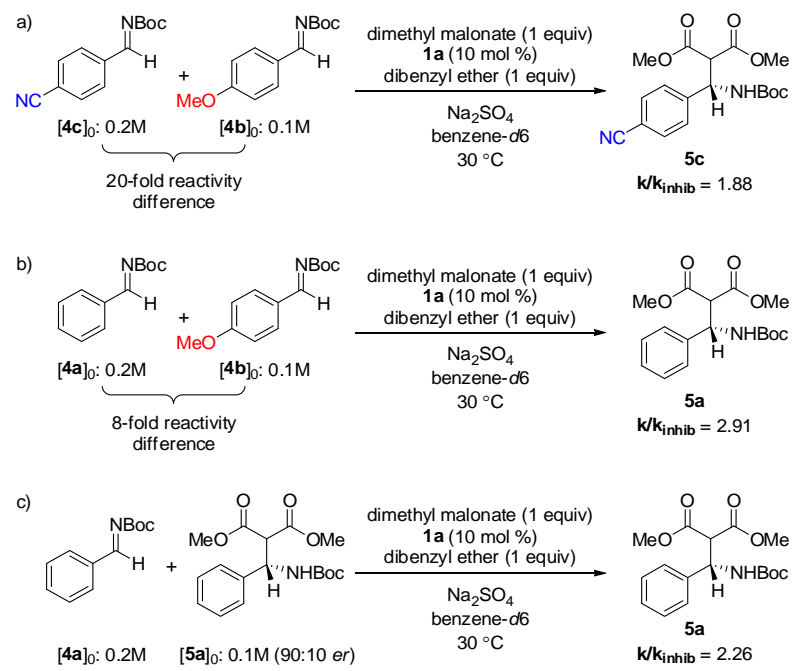

Scheme 3. Inhibition experiments carried out with a) $4 c$ and $4 b, b$ ) $4 a$ and $4 b$, and c) $4 a$ and $5 a$.

Finally, product inhibition with product $5 \mathrm{a}$ was also observed $\left(k / k_{\text {inhib }}=2.26\right.$, Scheme $\left.3 c\right)$, which justifies the need of an excess of imine to drive the reactions to completion.

C-C bond formation pathways. The details of the $\mathrm{C}-\mathrm{C}$ bond formation process in present Mannich reactions were explored computationally for the reaction $3 a+4 a$ promoted by foldamer catalyst 1a. We considered several possible mechanistic scenarios for this step that involve different substrate activation modes, and we found two feasible reaction pathways as illustrated in Figure 9.

On route 1, the deprotonated dimethyl-malonate is bound to the protonated amine and to the proximal $\mathrm{NH}$ group of thiourea, whereas the imine is activated via the distal $\mathrm{NH}$ group of the thiourea moiety of the catalyst. This type of substrate activation has already been described in our previous work, ${ }^{3 \mathrm{a}}$ and it has also been identified as the most favored pathway for organocatalytic vinylogous Michael reaction of $\alpha, \beta$-unsaturated-butyrolactam to chalcone.$^{6 e}$ On the other pathway, on route 2 , the deprotonated nucleophile is shifted to thiourea displaying double H-bonding interactions, and the electrophilic imine binds to the protonated amine unit via the carbonyl group of the Boc moiety.
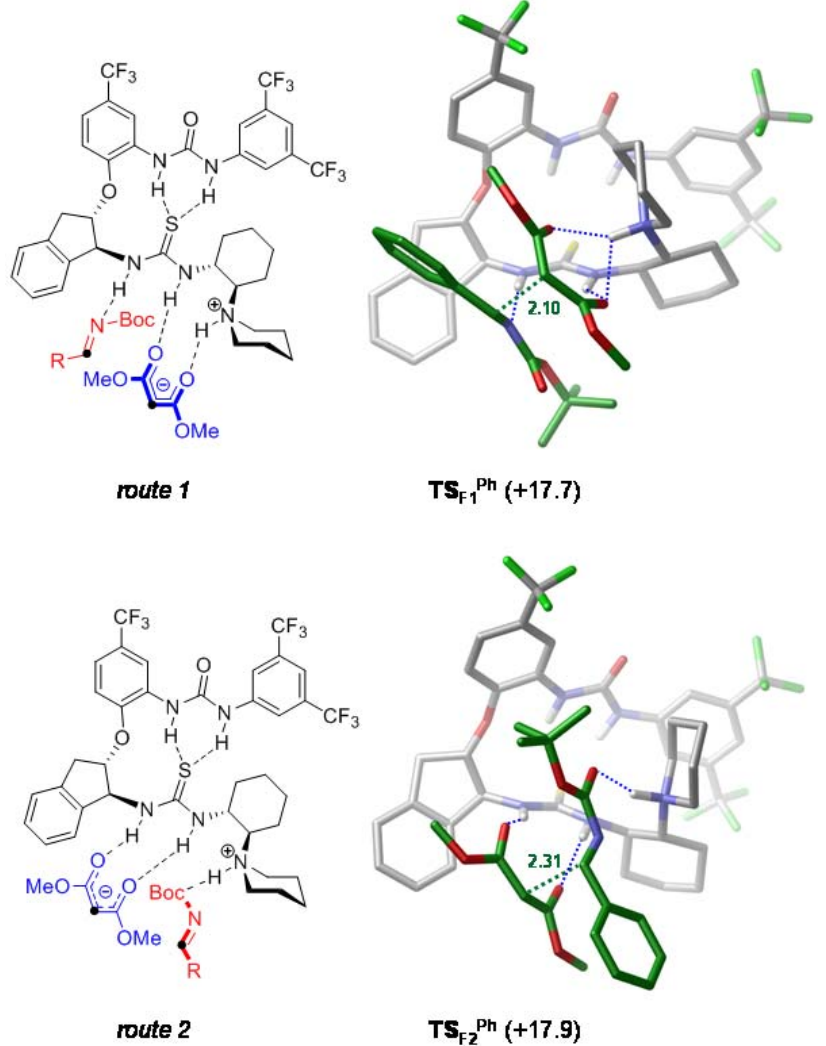

Figure 9. C-C bond formation pathways explored computationally for reaction $3 a+4 a$ catalyzed by $1 a$. In the schematic view, the carbon atoms involved in bond formation are labelled by black dots. Relative stabilities (solution phase Gibbs free energies with respect to reactant state $3 \mathbf{a}+4 \mathbf{a}+1 \mathbf{a}$; in $\mathrm{kcal} / \mathrm{mol}$ ) are given in parenthesis. Hydrogen bonds formed between the substrates and the catalyst are indicated by blue dotted lines, whereas the developing $\mathrm{C}-\mathrm{C}$ bond is illustrated by green dotted lines (related distances are given in Å). For clarity of images, hydrogen atoms are omitted, except those of $\mathrm{NH}$ groups.

The C-C bond formation transition states identified computationally on the two reaction pathways $\left(\mathrm{TS}_{\mathrm{F} 1}{ }^{\mathrm{Ph}}\right.$ and $\mathrm{TS}_{\mathrm{F} 2}{ }^{\mathrm{Ph}}$ in Figure 9) represent very similar barriers with respect to the $3 a+4 a+1 a$ reactant state (17.7 and $17.9 \mathrm{kcal} / \mathrm{mol}$, respectively) suggesting that both addition mechanisms might be operative in this particular reaction. ${ }^{19}$ This finding may seem surprising, but it actually supports the view formulated recently in our previous work that the application of a single reactivity model might not always be sufficient to describe the mechanism of bifunctional noncovalent organocatalysis. ${ }^{20}$

To test the two mechanistic scenarios against experimental data, calculations were carried out for analogous reactions with parasubstituted imines $\mathbf{4 b}$ and $4 \mathrm{c}$ as well. We find that both $\mathrm{C}-\mathrm{C}$ bond formation mechanisms account qualitatively for the observed reactivity trend. As shown in Table 3, the barriers predicted for the two pathways decrease gradually in the $4 \mathrm{~b}-\mathbf{4 a}-\mathbf{4 c}$ series, which is in line with the positive Hammett correlation. It is also apparent that computations predict nearly identical kinetic isotope effects for the two $\mathrm{C}-\mathrm{C}$ bond formation pathways, all equal or very close to 0.9 , which are in reasonable agreement with the measured data (see Table 2). These results thus provide further support for the relevance of parallel reaction channels in this Mannich reaction. 
Table 3. Computed barriers $\left(\Delta G^{\ddagger}\right.$; in $\left.\mathrm{kcal} / \mathrm{mol}\right)$ and kinetic isotope effects (KIE) for reactions with para-substituted aromatic imines. ${ }^{a}$

\begin{tabular}{llllll}
\hline & & \multicolumn{2}{c}{ route 1} & \multicolumn{2}{c}{ route 2 } \\
\cline { 3 - 6 } Imine & $\mathrm{R}$ & $\Delta G^{*}$ & $\mathrm{KIE}$ & $\Delta G^{*}$ & $\mathrm{KIE}$ \\
\hline 4b & $\mathrm{OMe}$ & 18.1 & 0.90 & 19.7 & 0.91 \\
$\mathrm{4a}$ & $\mathrm{H}$ & 17.7 & 0.90 & 17.9 & 0.90 \\
$4 \mathrm{c}$ & $\mathrm{CN}$ & 15.5 & 0.92 & 17.5 & 0.92 \\
\hline
\end{tabular}

a The barriers refer to reactions with non-deuterated imines.

Comparative analysis. To gain insight into the origin of the unprecedented reactivity of foldamer catalysts in Mannich reactions with aliphatic aldimines, we performed a comparative computational analysis for reactions $3 a+4 a$ and $3 a+4 d$ catalyzed by bifunctional organocatalysts $1 \mathrm{a}$ and $\mathbf{2 a}$. The computed barriers associated with the two $\mathrm{C}-\mathrm{C}$ bond formation mechanisms are collected in Figure 10.
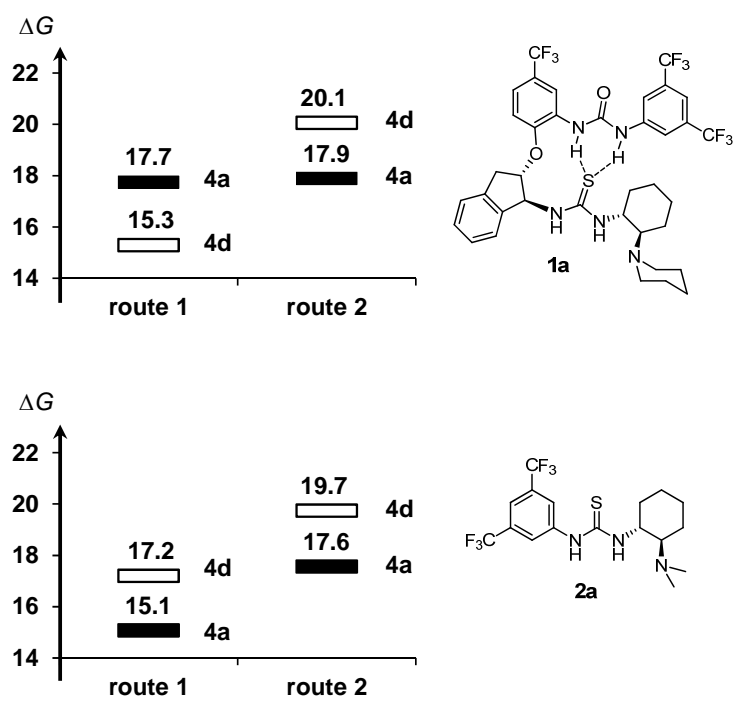

Figure 10. Computed C-C bond formation barriers (in $\mathrm{kcal} / \mathrm{mol}$ ) for reactions $3 \mathrm{a}+4 \mathrm{a}$ (filled bars) and $3 \mathrm{a}+\mathbf{4 d}$ (empty bars) promoted by catalysts $1 \mathrm{a}$ and $2 \mathrm{a}$.

Note first that the foldamer catalyst 1a offers a kinetically favored pathway for the reaction with aliphatic imine $4 \mathrm{~d}$ as well, since the barrier computed on route 1 is only $15.3 \mathrm{kcal} / \mathrm{mol}$, which is actually lower than that computed for $4 \mathrm{a}$. On the other hand, route 2 becomes less accessible in this reaction as expected from the increased barrier $(20.1 \mathrm{kcal} / \mathrm{mol})$. The free energy data obtained for analogous reactions catalyzed by the Takemoto catalyst 2 a reveal a different pattern in the diagram. The barriers on route 1 are found to be notably lower for both substrates, and the reaction with aromatic imine 4a is predicted to be kinetically more favored on both reaction pathways.

Although these results corroborate the diverse catalytic effect of the two catalysts in the $3 a+4 a$ and $3 a+4 d$ reactions, and they point to an enhanced reactivity of $4 \mathrm{~d}$ with the foldamer catalyst, the computed barriers are not fully consistent with the results of com- petition experiments (Figure 2). The reactivity difference between $4 \mathrm{a}$ and $4 \mathrm{~d}$ is reasonably well reproduced for the Takemoto catalyst, but computations seem to overestimate the reactivity of $4 \mathrm{~d}$ for the foldamer catalyst. ${ }^{21}$ The quantitative discrepancy between the computed barriers and the observed rates could be related to the inaccuracy of the applied computational method, which might be considerable particularly for large molecular models involving the bulky catalyst $1 \mathbf{a}^{22}$

In addition to computational errors, the apparent discrepancy might be due to mechanistic events beyond the $\mathrm{C}-\mathrm{C}$ bond formation step, so we examined the mechanism of reprotonation as well for the reaction $3 a+4 a$. This step involves a proton shift from the protonated amine unit of the catalyst to the $\mathrm{N}$ atom of the anionic adduct intermediate formed in the $\mathrm{C}-\mathrm{C}$ bond formation step. We find that proton transfer occurs very easily on route 2 because the $\mathrm{N}$ atom of the adduct lies in close vicinity of the protonated amine (see $\mathrm{TS}_{\mathrm{F} 2}{ }^{\mathrm{Ph}}$ in Figure 9) ${ }^{23}$ On route 1, however, substantial structural rearrangement in the $\mathrm{H}$-bonded network of this intermediate is required prior to proton transfer (see $\mathrm{TS}_{\mathrm{F} 1}{ }^{\mathrm{ph}}$ in Figure 9). This rearrangement and subsequent reprotonation is still facile with the Takemoto catalyst, however, it appears to be hindered with the bulky foldamer catalyst. The difference found for the two catalysts is clearly due to the presence of the urea sidegroup in catalyst 1a, which imposes restriction on intramolecular structural rearrangements needed for reprotonation. Potential energy scan calculations suggest that transition states of this multistep rearrangement process may lie above $\mathrm{TS}_{\mathrm{F} 1}{ }^{\mathrm{Ph}}$, so the $3 \mathrm{a}+4 \mathrm{a}$ reaction may preferentially follow route 2 with catalyst $1 a^{24}$ In the $3 \mathrm{a}+4 \mathrm{~d}$ reaction, the reprotonation steps on route 1 is likely hindered too, but this pathway could be still favored over route 2 ,. It is therefore possible that the reactions with the two imines (4a and 4d) take place via two different pathways (route 2 and route 1 , respectively) but with comparable rates. We recall that experimentally, in the reaction with aromatic imines $(4 a-4 c)$, the $\mathrm{C}-\mathrm{C}$ bond formation is clearly rate-limiting, but the same may not hold true with aliphatic imine 4d. Unfortunately, reliable KIE analysis could not be performed for imine $4 \mathrm{~d}$ due to side reactions.

On the beneficial role of the foldamer catalyst. To provide further understanding for the beneficial effect of catalyst 1a on the C$\mathrm{C}$ bond formation barrier for imine $4 \mathrm{~d}$ we analyzed the structures and the nature of interactions in transition states located on route 1 (see Figure 11).

We note first that the intramolecular hydrogen bonds between urea and thiourea in $\mathrm{TS}_{\mathrm{F} 1}{ }^{\mathrm{Ph}}$ and $\mathrm{TS}_{\mathrm{Fl}}{ }^{\mathrm{Cy}}$ are notably strengthened as compared to the free foldamer catalyst (see Figure 3), which is an evidence for the cooperativity, but these changes alone do not account for the improved reactivity for aliphatic imines. Cooperative effects amplify the acidity of the thiourea unit in foldamer catalysts, ${ }^{25}$ which is likely beneficial for both aromatic and aliphatic imines, however, this does not translate to increased reactivity for aromatic imines, but only for aliphatic imines. 

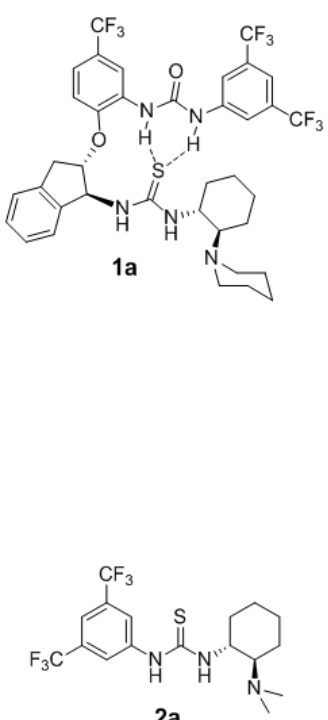

2a

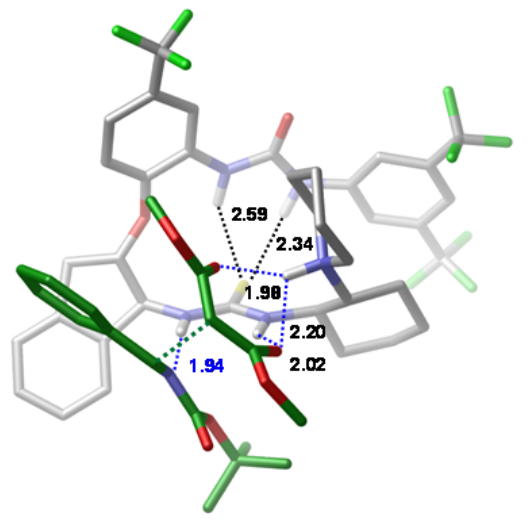

$\mathrm{TS}_{\mathrm{F} 1}^{\mathrm{Ph}}(+17.7)$

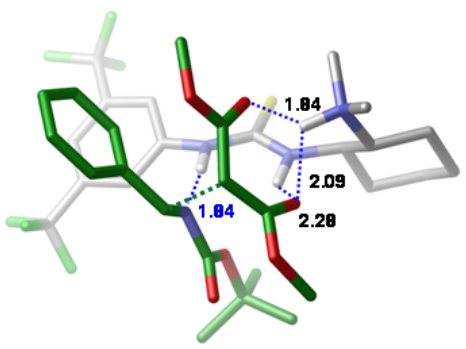

$\mathrm{TS}_{\mathrm{T} 1}^{\mathrm{Ph}}(+15.1)$

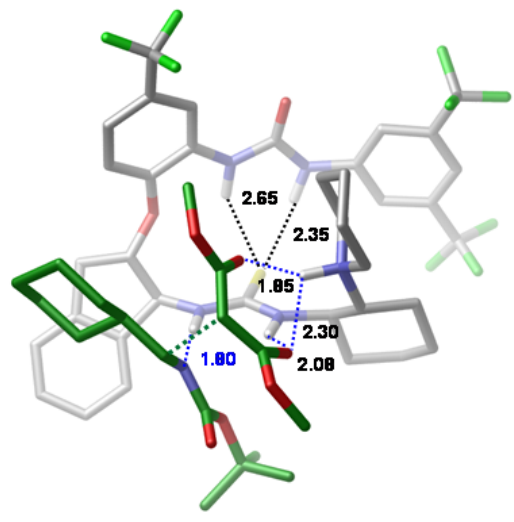

$\mathrm{TS}_{\mathrm{F} 1} \mathrm{Cy}_{\mathrm{y}}(+15.3)$

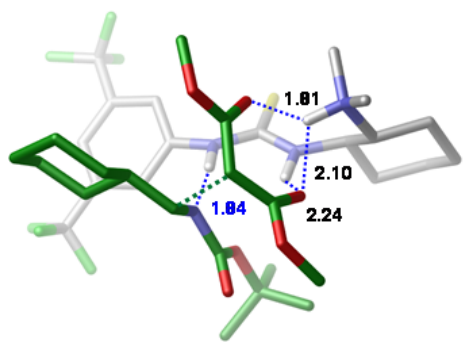

$\mathrm{TS}_{\mathrm{T} 1} \mathrm{Cy}_{\mathrm{y}}(+17.2)$

Figure 11. Bond distances (in $\AA$ ) characteristic of H-bonding interactions in C-C bond formation transition states on route 1 in reactions $3 a+4 a$ and $3 a+4 d$ promoted by catalysts $1 \mathrm{a}$ (upper structures) and $2 \mathrm{a}$ (lower structures). Catalyst-substrate interactions are indicated in blue, intramolecular urea-thiourea interactions are in black. Relative stabilities (in kcal/mol; with respect to reactants) are given in parenthesis.
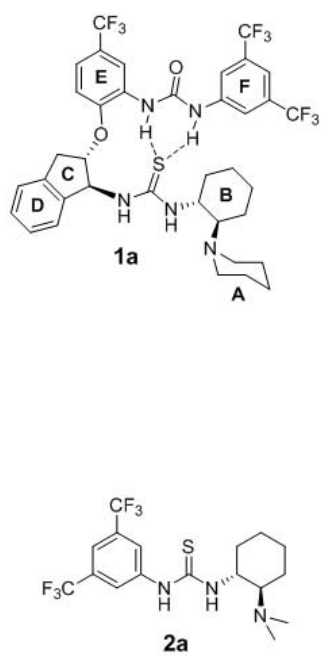

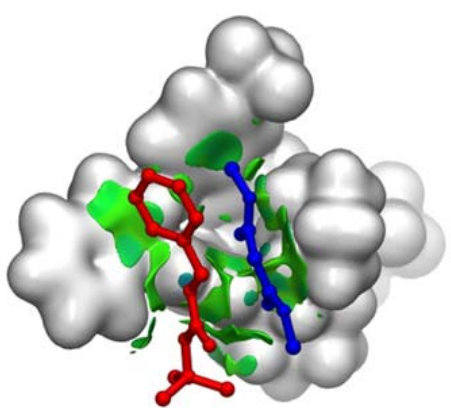

$\mathrm{TS}_{\mathrm{F} 1} \mathrm{Ph}$

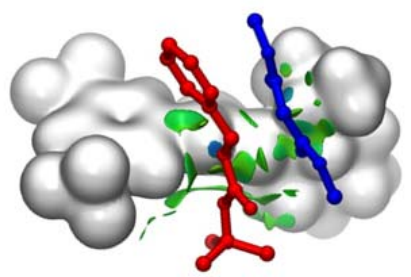

$\mathrm{TS}_{\mathrm{T} 1} \mathrm{Ph}$

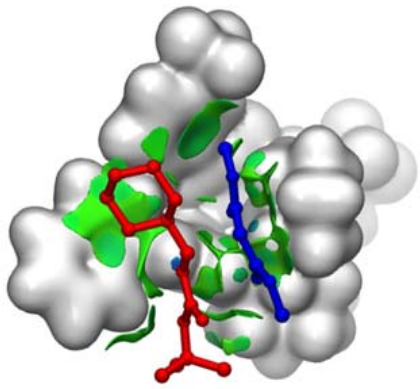

$\mathrm{TS}_{\mathrm{F} 1} \mathrm{Cy}$

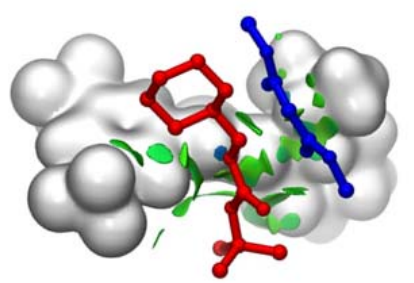

$\mathbf{T S}_{\mathrm{T} 1} \mathrm{Cy}_{\mathbf{y}}$

Figure 12. Noncovalent contacts in $\mathrm{C}-\mathrm{C}$ bond formation transition states on route 1 in reactions $3 \mathrm{a}+4 \mathrm{a}$ and $3 \mathrm{a}+4 \mathrm{~d}$ promoted by catalysts $1 \mathrm{a}$ (upper structures) and $2 \mathrm{a}$ (lower structures). Protonated catalyst is represented via an isodensity surface $(\rho=0.01$ au), imines $4 \mathrm{a}$ and $4 \mathrm{~d}$ are highlighted in red, malonate $3 \mathrm{a}$ in blue. Green regions represent weak noncovalent interactions as obtained from NCI analysis. Applied cutoff for reduced density gradient is $\mathrm{s}=0.3 \mathrm{au}$. 
In transition states involving the Takemoto catalyst $\left(\mathrm{TS}_{\mathrm{T} 1}{ }^{\mathrm{Ph}}\right.$ and $\mathrm{TS}_{\mathrm{T} 1}{ }^{\mathrm{Cy}}$ ) the binding of reacting partners is very similar, as indicated by the distances characteristic of $\mathrm{H}$-bonding interactions (e.g. both imines form hydrogen bonds with a distance of $1.84 \AA$ ). In contrast, there are notable differences in these distances in transition states involving the foldamer catalyst $1 \mathrm{a}\left(\mathrm{TS}_{\mathrm{F} 1}{ }^{\mathrm{Ph}}\right.$ and $\left.\mathrm{TS}_{\mathrm{F1}}{ }^{\mathrm{Cy}}\right)$, and they show a more compact binding for aliphatic imine $4 \mathrm{~d}$. For instance, the $\mathrm{N}-\mathrm{H} \cdots \mathrm{N}$ hydrogen bond associated with the activation of imine $4 \mathrm{~d}$ is significantly elongated in $\mathrm{TS}_{\mathrm{F}}{ }^{\mathrm{Ph}}$ and it is shorter in $\mathrm{TS}_{\mathrm{F} 1}{ }^{\mathrm{Cy}}$ (1.94 and $1.80 \AA$, respectively). The longer $\mathrm{N}-\mathrm{H} \cdots \mathrm{N}$ hydrogen bond in $\mathrm{TS}_{\mathrm{F} 1}{ }^{\mathrm{Ph}}$ is consistent with the trend obtained for relative stabilities of the transition states and suggests that the foldamer catalyst cannot accommodate aromatic imines as efficiently as aliphatic imines into the catalytic pocket.

Figure 12 shows another representation of the four transition states, and highlights the differences in noncovalent interactions between the catalyst and the evolving adduct species. It is apparent that the $\mathrm{Ph} / \mathrm{Cy}$ groups of the imines and the Me substituents of dimethyl-malonate have practically no contact with catalyst 2a, but these groups do interact with various parts of catalyst $1 \mathrm{a}$. The presence of the urea side group in catalyst 1a provides a well-defined binding pocket for the reacting substrates, which induces selectivity with respect to imine substitution. The cyclohexyl moiety of $4 \mathrm{~d}$ seems to accommodate more favorably into this pocket than the flat and more rigid phenyl group of $4 a$, presumably because the more flexible cyclohexyl ring can bend and fit in the binding pocket generated by the rings $\mathrm{C}, \mathrm{D}$ and $\mathrm{E}$ of the catalyst. This is also visible from the more extended contact surface in $\mathrm{TS}_{\mathrm{F} 1}{ }^{\mathrm{Cy}}$. The longer $\mathrm{N}-\mathrm{H} \cdots \mathrm{N}$ distance in $\mathrm{TS}_{\mathrm{F} 1}{ }^{\mathrm{Ph}}$ compared to $\mathrm{TS}_{\mathrm{F} 1}{ }^{\mathrm{Cy}}$ (and also compared to $\mathrm{TS}_{\mathrm{Tl}_{1}}^{\mathrm{Ph}}$ ) imp, lies destabilizing steric hindrance.

The role of the urea side-group in catalytic selectivity was further analyzed by calculations carried out for model catalysts derived from 1a (Scheme 4).
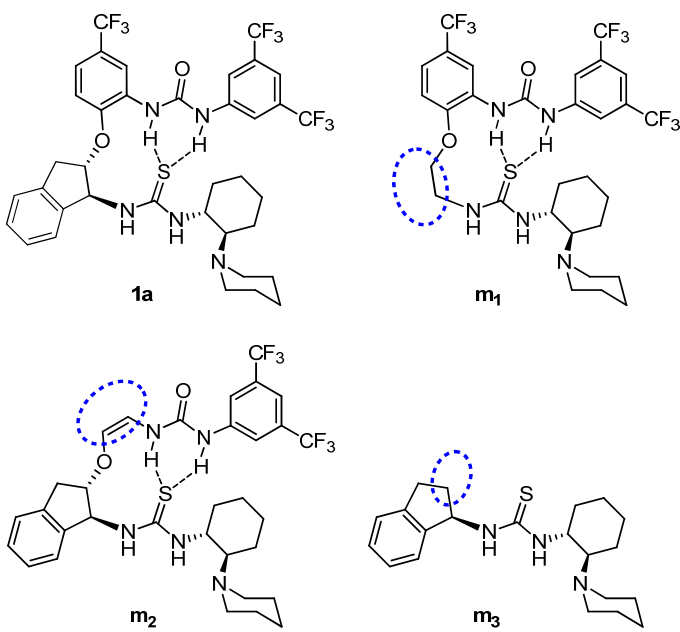

Scheme 4. Model catalysts derived from 1a. Units altered with respect to the original catalyst are highlighted in blue.

$\mathrm{C}-\mathrm{C}$ bond formation transition states analogous to $\mathrm{TS}_{\mathrm{Fl}}{ }^{\mathrm{Ph}}$ and $\mathrm{TS}_{\mathrm{F} 1}{ }^{\mathrm{Cy}}$ were computed for each model. The barriers related to the identified transition states are listed in Table 4.
Table 4. Computed Barriers and their Differences Obtained for Model Catalysts. ${ }^{2}$

\begin{tabular}{cccc}
\hline catalyst & $\Delta G^{P h}$ & $\Delta G^{C y}$ & $\Delta \Delta G=\Delta G^{C y}-\Delta G^{P h}$ \\
\hline 1a & 17.7 & 15.3 & -2.4 \\
m $_{1}$ & 18.5 & 18.6 & +0.1 \\
m $_{2}$ & 17.9 & 18.3 & +0.4 \\
m $_{3}$ & 19.9 & 21.1 & +1.2 \\
no cat & 11.8 & 14.9 & $+3.1^{\mathrm{b}}$
\end{tabular}

${ }^{\text {a }} \Delta G^{P h}$ and $\Delta G^{C y}$ refer to barriers computed for aromatic and aliphatic imines (4a and $4 d) .{ }^{b}$ In the absence of catalyst, the barriers are computed relative to the $3 \mathrm{a}^{-}+$imine state.

As reported above, the barriers computed for imines $4 \mathrm{a}$ and $4 \mathrm{~d}$ with the original catalyst (1a) are 17.7 and $15.3 \mathrm{kcal} / \mathrm{mol}$ giving $\Delta \Delta G=-2.4 \mathrm{kcal} / \mathrm{mol}$ as a difference. The presence of the indene ring and the neighbouring $\mathrm{CF}_{3}$-substituted phenyl group appears to be important in getting enhanced reactivity with $4 \mathrm{~d}$, because without these groups (models $\mathrm{m}_{1}$ and $\mathrm{m}_{2}$ ) the computed $\Delta \Delta G$ is close to zero (similar barriers for $4 \mathrm{a}$ and $4 \mathrm{~d}$ ). The elimination of the entire urea side-group (model $\mathrm{m}_{3}$ ) gives $\Delta \Delta G=+1.2 \mathrm{kcal} / \mathrm{mol}$, so the catalysis becomes less efficient for the aliphatic imine similarly to that with Takemoto catalyst $2 \mathrm{a}$ (for which $\Delta \Delta G=+2.1$ $\mathrm{kcal} / \mathrm{mol})$. We note that in the absence of catalyst, the C-C bond formation is clearly favored for the aromatic imine $(\Delta \Delta G=+3.1$ $\mathrm{kcal} / \mathrm{mol}){ }^{26}$

Our computational analysis thus suggest that the improved catalytic performance of foldamer catalysts in Mannich reactions with aliphatic imines cannot be explained solely by the cooperative effects of intramolecular $\mathrm{H}$-bonding interactions between urea and thiourea, although cooperativity is clearly evident in the shortening of the intramolecular H-bonds in the transition states. The structural fit of the substrates to the binding pocket of the folded structure appears to be better with the aliphatic imines, and this also contributes to their higher reactivity.

Catalyst deactivation and substrate isomerization. To further rationalize the differences between the catalysts $1 \mathrm{a}$ and $2 \mathrm{a}$, we examined whether the aliphatic imines might suffer additional disadvantages with catalyst $2 \mathrm{a}$ that are not present with $1 \mathrm{a}$. We were especially concerned about potential side reactions, which were investigated by using a less-hindered and more reactive imine $4 \mathrm{e}$ (Scheme 5).

Indeed, we observed isomerization of the imine $4 \mathrm{e}$ to the enamine (6) form with catalyst $2 \mathrm{a}$ (Scheme 5). This isomerization leads to low conversion as the isomerization is irreversible in the reaction conditions. Previously, Takemoto and coworkers have noted that problems with the bifunctional thiourea catalyst ${ }^{27}$ can be avoided if the highly nucleophilic thiourea moiety is replaced with a less nucleophilic H-bond donor. ${ }^{28}$

The effect of the catalysts on the isomerization reaction was studied in more detail by ${ }^{1} \mathrm{H}$ NMR monitoring (Scheme 5a). Mixing an aliphatic imine $4 \mathrm{e}$ and catalyst $2 \mathrm{a}$ in 1:1 ratio in benzene led to immediate disappearance of the imine related peaks. In addition, most of the catalyst had formed a new species 7 that was stable enough to be detected on the ${ }^{1} \mathrm{H}$ NMR timescale. The degradation 
of this new species was directly related to formation of the enamines 6 and also to an increase in the catalyst peak integrals.

Mixing imine $4 \mathrm{e}$ with 2-mercaptopyridine resulted in a stable product (8) that could be fully characterized with NMR (Scheme $5 b$, see Supporting Information). ${ }^{1} \mathrm{H},{ }^{13} \mathrm{C}, \mathrm{COSY}$ and $\mathrm{HMQC}$ measurements were all consistent with a 1,2-addition product of 2mercaptopyridine to imine $4 \mathrm{e}$. The stability of this product implies that the amine base in Takemoto catalyst is necessary for the adduct to decompose.

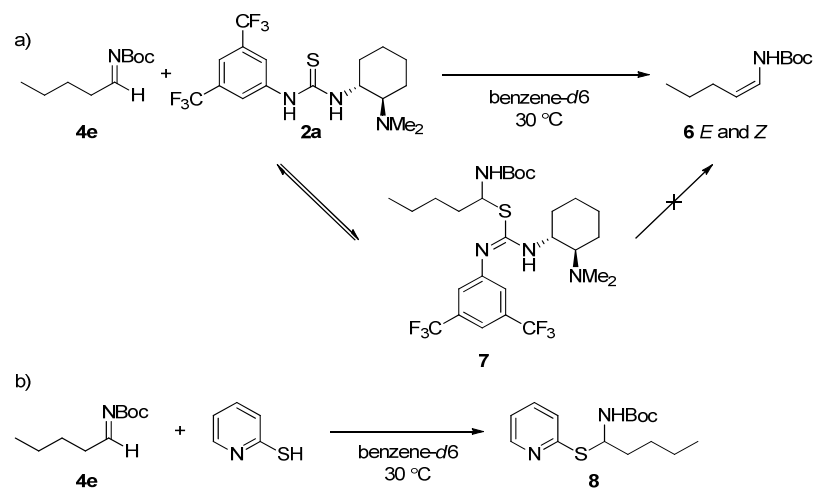

Scheme 5. Deactivation of catalyst 2a: a) isomerization of imine $4 e$, and $b$ ) addition of 2 -mercaptopyridine to $4 \mathrm{e}$.

When the isomerization experiment was conducted with 20 mol\% of $2 \mathrm{a}$ the isomerization process was sluggish as only $73 \%$ conversion was obtained after $2 \mathrm{~h}$ (Table 5 ). However, a urea version of the Takemoto catalyst $(\mathbf{2 b})$ was more effective in the isomerization process while no covalently bound species could be observed in the ${ }^{1} \mathrm{H}$ NMR spectra.

Table 5. Isomerization of Aliphatic Imine with Bifunctional Organocatalysts

\begin{tabular}{|c|c|c|c|}
\hline$\underbrace{N B o c}_{4 e}$ & $\begin{array}{c}\text { catalyst }(20 \mathrm{~mol} \%) \\
\text { benzene-d6 } \\
30^{\circ} \mathrm{C}\end{array}$ & $\int_{z-6}^{N H B o c}+1$ & $N_{E-6}^{N}$ \\
\hline Catalyst & Conversion (\%) & Time (min) & $\mathrm{E}: Z$ \\
\hline $1 \mathrm{a}$ & 80 & 120 & $1: 1.5$ \\
\hline $1 b$ & 100 & $<8$ & $3.8: 1$ \\
\hline $2 a$ & 73 & 120 & $1: 1.2$ \\
\hline $2 b$ & 97 & 40 & $1: 1.8$ \\
\hline $\mathrm{Et}_{3} \mathrm{~N}$ & 6 & 120 & $1: 2.1$ \\
\hline
\end{tabular}

Catalyst $\mathbf{2 b}$ also produced the enamine in higher $Z$ selectivity than Takemoto catalyst. Surprisingly, the foldamer catalyst $\mathbf{l b}$ was found to be the most effective in the isomerization of the imine to the enamine, implying that the isomerization process is favored by stronger $\mathrm{H}$-bond donors. In addition, the selectivity for the double bond was inversed to favor the $E$ enamine. With the bulkier piperidine catalyst (1a) the rate of isomerization was much slower than with the $N$-dimethylamine foldamer catalyst (1b) and the $E: Z$ selectivity was also close to those obtained with $2 \mathrm{a}$ and $2 \mathrm{~b}$. These results demonstrate that blocking the sulfur atom of the catalyst by the foldamer structure does not solve the isomerization problem.
Overall, the deactivation and isomerization experiments suggest that the reactivity difference between the foldamer catalysts $1 \mathrm{a}$ and $\mathbf{1 b}$ and Takemoto catalyst $2 \mathrm{a}$ could at least partially be attributed to the nucleophilicity of the sulfur atom in $2 \mathrm{a}$, resulting in fast but reversible deactivation of the catalyst by the aliphatic imine such as $4 \mathrm{e}$. In catalysts $1 \mathrm{a}$ and $1 \mathrm{~b}$, the intramolecular hydrogen bonds and the folding may completely block the nucleophilic attack of the thiourea sulfur and thus prevents deactivation of the catalyst. Isomerization of the imine appears to be a side reaction that is common to all catalysts. A control experiment with triethylamine showed that aliphatic imines are relatively stable under moderately basic non-nucleophilic conditions. The imine-to-enamine isomerization appears to require the presence of $\mathrm{H}$-bond donors in the catalyst.

Conclusions. The folded structure of the foldamer ureathiourea-tertiary amine catalyst 1a was confirmed by solution, solid state NMR and computational analyses, both in the free state as well as when complexed with the imine substrate or in an intramolecular salt form with substrate analogues (acac or hfacac). In all cases, evidence for the folded structure could be readily inferred from the structural data.

In competition experiments, aliphatic imine $4 \mathrm{~d}$ and aromatic imine $4 \mathrm{a}$ reacted at comparable rates with dimethyl malonate when the foldamer catalysts $1 \mathrm{a}$ or $1 \mathrm{~b}$ were used. In contrast, with $2 \mathrm{a}$ and its urea variant $2 \mathrm{~b}, 4 \mathrm{~d}$ reacted very slowly as compared to $4 \mathrm{a}$.

The Hammett plot and the secondary kinetic isotope effects measured for the Mannich reaction with aromatic imines supported a mechanism where the $\mathrm{C}-\mathrm{C}$ bond forming event is the turnover-limiting step. Computational studies revealed two viable $\mathrm{C}-\mathrm{C}$ bond formation pathways in these reactions, route 1 and route 2 , that differ by the alternate activation modes of the malonate and imine substrates. For aliphatic imine $4 \mathrm{~d}$ bearing a cyclohexyl group, route 1 allows a kinetically favored $\mathrm{C}-\mathrm{C}$ bond formation process as well, which is found to be a unique feature of foldamer catalyst 1a. For reactions with Takemoto catalyst, computations predict significantly reduced reactivity of $4 \mathrm{~d}$ as compared to aromatic imines $4 \mathrm{a}-$ c, which is in line with experimental observations. Our computational analysis suggests that in addition to $\mathrm{H}$-bonding interactions, the foldamer catalyst can further facilitate the $\mathrm{C}$ - $\mathrm{C}$ bond formation via dispersion forces provided by the catalyst's binding pocket. These stabilizing noncovalent interactions are scarcely present in $\mathrm{C}-\mathrm{C}$ bond formation transition states with simpler thiourea-tertiary amine catalysts. These differences may explain the improved performance of the foldamer catalyst with aliphatic imines.

The folded structure of catalysts $1 \mathrm{a}$ and $1 \mathrm{~b}$ also helps to block the nucleophilicity of the thiourea sulfur atom, preventing catalyst deactivation via nucleophilic attack to imines. This provides an additional reason for the improved catalytic performance of the foldamer catalysts in the Mannich reactions with aliphatic imines.

In summary, the results obtained herein point to the importance of the folded structure with an active site cleft, in contrast to cooperative effects associated with the intramolecular hydrogen bond, as the explanation for the enhanced reactivity of foldamer catalyst $1 \mathrm{a}$ and $\mathrm{lb}$ with aliphatic imines.

\section{AUTHOR INFORMATION}

\section{Corresponding Author}

papai.imre@ttk.mta.hu, petri.pihko@jyu.fi 


\section{ASSOCIATED CONTENT}

Supporting Information. Experimental procedures, additional experiments pertaining to the mechanism, characterization data, computational details, and copies of NMR spectra and GC chromatograms.

\section{ACKNOWLEDGMENT}

Financial support from the Academy of Finland (project \#259532), University of Jyväskylä (postgraduate fellowship to A. J. N.), and the Hungarian Scientific Research Fund (OTKA, grant K-112028) are gratefully acknowledged. Computer facilities provided by NIIF HPC Hungary (project 85708 kataproc) is also acknowledged. We thank Dr. Elina Kalenius and Ms. Johanna Lind for assistance with mass spectrometry and Mr. Esa Haapaniemi for NMR assistance.

\section{REFERENCES}

1. For related discussions, see: (a) Frey, P. A.; Hegeman, A. D. Enzymatic Reaction Mechanisms, Oxford University Press, Oxford, 2007. (b) Petsko, G. A.; Ringe, D. In: Protein Structure and Function, New Science Press, London, 2004.

2. For reviews, see: (a) Pihko, P. M.; Rahaman, H., Bifunctional AcidBase Catalysts. In: Enantioselective Organocatalyzed Reactions 1, R. Mahrwald Ed., Springer, Heidelberg, 2011, pp. 185-207. (b) Takemoto, Y.; Inokuma, T. Bifunctional Thiourea Catalysts. In: Asymmetric Synthesis II: More Methods and Applications, Christmann, M.; Bräse, S. Ed., WileyVCH, Weinheim, 2012, pp. 233-237. (c) Claraz, A.; Siitonen, J. H..; Pihko, P. M. Iminium catalysis. In: Lewis Base Catalysis in Organic Synthesis; Vedejs, E.; Denmark S. Ed., Wiley-VCH, Weinheim, 2016, Vol 2, pp. 805856.

3. (a) Probst, N.; Madarász, Á.; Valkonen, A.; Pápai, I.; Rissanen, K.; Neuvonen, A.; Pihko, P. M. Angew. Chem. Int. Ed. 2012, 51, 8495-8499. (b) Neuvonen, A. J.; Pihko, P. M. Org. Lett.2014, 16, 5152-5155.

4. (a) Okino, T.; Hoashi, Y.; Takemoto, Y. J. Am. Chem. Soc. 2003, 125, 12672-12673. (b) Okino, T.; Hoashi, Y.; Furukawa, T.; Xu, X.; Takemoto, Y. J. Am. Chem. Soc. 2005, 127, 119-125.

5. (a) Jones, C. R.; Pantoş, G.D.; Morrison, A. J.; Smith, M. D. Angew. Chem. Int. Ed. 2009, 48, 7391-7394. (b) So, S. S.; Burkett, J. A.; Mattson, A. E. Org. Lett. 2011, 13, 716-719. (c) A recent review on the topic: Auvil, T. J.; Schafer, A. G.; Mattson, A. E. Eur. J. Org. Chem. 2014, 2633-2646.

6. (a) Hamza, A.; Schubert, G.; Soós, T.; Pápai, I. J. Am. Chem. Soc. 2006, 128, 13151-13160. (b) Hammar, P.; Marcelli, T.; Hiemstra, H.; Himo, F. Adv. Synth. Catal. 2007, 349, 2537-2548. (c) Almasi, D.; Alonso, D. A.; Gómez-Bengoa, E.; Nájera, C. J. Org. Chem. 2009, 74, 6163-6168. (d) Tan, B.; Lu, Y.; Zeng, X.; Chua, P. J.; Zhong, G. Org. Lett. 2010, 12, 2682-2685. (e) Zhu, J.-L.; Zhang, Y.; Liu, C.; Zheng, A.-M.; Wang, W. J. Org. Chem. 2012, 77, 9813-9825. (f) Han, X.; Lee, R.; Chen, T.; Luo, J.; Lu, Y.; Huang, K. W. Sci. Rep. 2013, 3, 2557. (g) Azuma, T.; Kobayashi, Y.; Sakata, K.; Sasamori, T.; Tokitoh, N.; Takemoto, Y. J. Org. Chem. 2014, 79, 1805-1817. (h) Žabka, M.; Šebesta, R. Molecules 2015, 20, 15500. (i) Grayson, M. N.; Houk, K. N. J. Am. Chem. Soc. 2016, 138, 1170-1173.

7. (a) Huynh, P. N. H.; Walvoord, R. R.; Kozlowski, M. C. J. Am. Chem. Soc. 2012, 134, 15621-15623. (b) Walvoord, R. R.; Hyunh, P. N. H.; Kozlowski, M. C. J. Am. Chem. Soc. 2014, 136, 16055-16065.

8. X-ray structure of $1 \mathrm{~b}$ and its hfacac salt have been published in ref $3 \mathrm{a}$.

9. In our computational analysis, most of the DFT calculations (geometry optimizations, vibrational analysis, estimation of solvent effects) were carried out at the M06-2X/6-311G(d,p) level of theory. For each located structure, we carried out additional single-point energy calculations using the same functional along with the larger 6-311++G(3df,3pd) basis set. The reported energetics refers to relative solution-phase Gibbs free energies (with benzene as a solvent). For further details, see Supporting Information.

10. For details of the conformational analysis, see Supporting Information.

11. For the corresponding transition state, see Supporting Information. The experimentally observed ion-pair complex formed between catalyst 1a and $h$ facac is predicted to $10.4 \mathrm{kcal} / \mathrm{mol}$ more stable than the reactant state.
12. Two different $O$-coordinated structures of complex $1 \mathrm{a} \cdot 4 \mathrm{a}$ were also identified computationally both lying about $2 \mathrm{kcal} / \mathrm{mol}$ higher than the $N$ coordinated form.

13. Entropic loss appears to be more important upon the coordination of the methoxy substituted imine $4 \mathrm{~b}$ (rotational degrees of freedom of the OMe group are constrained in the $1 \mathrm{a} \cdot \mathbf{4} \mathrm{b}$ complex. The expected stability trend is well reproduced in terms of the binding energies computed from the electronic energies $(-20.9,-19.5$ and $-18.5 \mathrm{kcal} / \mathrm{mol}$, for the $4 \mathrm{~b}, 4 \mathrm{a}$ and $4 \mathrm{c}$ series.

14. Formation of exocyclic double bonds to a 6-membered ring is known to be less favorable than acyclic double bonds and as such isomerization to form the enamine is disfavoured with $4 \mathrm{~d}$ compared to other aliphatic imines. For a discussion see: Brown, H. C.; Brewster, J. H.; Shechter, H. J. Am. Chem. Soc. 1954, 76, 467-474.

15. See the Supporting Information for details about rate measurements and initial rate determination.

16. The reaction progress was followed by ${ }^{1} \mathrm{H}$ NMR and the data obtained were analyzed by linear regression of first measurement points, i.e. the method of initial rates. See the Supporting Information for details.

17. Gajewski, J. J.; Ngernmeesri, P. Org. Lett. 2000, 2, 2813-2815.

18. For the basic concepts of the energetic span model, see: Kozuch, S.; Shaik, D. Acc. Chem. Res. 2011, 44, 101-110.

19. Although the analysis of stereoselectivity was not in the main focus of the present study, we examined possible pathways towards the minor enantiomeric product as well. The most favored transition state corresponds to activation mode of route 1 lying at $25.8 \mathrm{kcal} / \mathrm{mol}$ in free energy implying that the sense and the high degree of enantioselectivity is reproduced by computations (for details, see Supporting Information).

20. B. Kótai, G. Kardos, A. Hamza, V. Farkas, I. Pápai, T. Soós, Chem. Eur. J., 2014, 20, 5631-5639.

21. Based on the results of competition experiments (see Figure 2), one expects similar or slightly lower barrier for reaction with aromatic imine $4 \mathrm{a}$. 22. Test calculations carried out with the $\omega B 97 X-D$ functional give similar trends for the $\mathrm{C}-\mathrm{C}$ bond formation barriers suggesting that the discrepancy is probably not related to the choice of the approximated energy functional (for details, see Supporting Information).

23. C-C bond formation transition states and subsequent adduct intermediates show a close structural resemblance (for details, see Supporting Information).

24. The adequate description of the full pathway from the ion-pair intermediate formed on route 1 to the reprotonation transition state is challenging for large model used herein, because the structural rearrangement likely involves several steps. In our present work, we performed potential energy scan calculations using a single structural parameter, namely the distance between the adduct $\mathrm{N}$ atom and the $\mathrm{H}$ atom of the protonated amine. This simple approach can provide only an upper limit for the barrier of structural rearrangement.

25. Computations predict very similar acidities of thiourea in catalysts 1a and $2 \mathrm{a}$. Despite the aliphatic nature of the indene linker in $1 \mathrm{a}$, the $\mathrm{pK}_{\mathrm{a}}$ of the $\mathrm{N}-\mathrm{H}$ group that binds the imine on route 1 is computed to be only 1.1 unit higher than that in 2a. For acidity enhancement via internal activation, see: Couch, E. D.; Auvil, T. J.; Mattson, A. E. Chem. Eur. J., 2014, 20, 82838287.

26. The barriers computed in the absence of catalyst are low because they do not involve the deprotonation and catalyst binding processes, which are both endergonic.

27. Xu, X.; Yabuta, T.; Yuan, P.; Takemoto, Y. Synlett, 2006, 137-140.

28. (a) Inokuma, T.; Furukawa, M.; Uno, T.; Suzuki, Y.; Yoshida, K.; Yano, Y.; Matsuzaki, K.; Takemoto, Y. Chem. Eur. J. 2011, 17, 1047010477. (b) Inokuma, T.; Furukawa, M.; Suzuki, Y.; Kimachi, T.; Kobayashi, Y.; Takemoto, Y. ChemCatChem 2012, 4, 983-985. (c) Xiao, H.; Kobayashi, Y.; Takemoto, Y.; Morokuma, K. ACS Catal. 2016, 6, 2988-2996. 
TOC graphic:

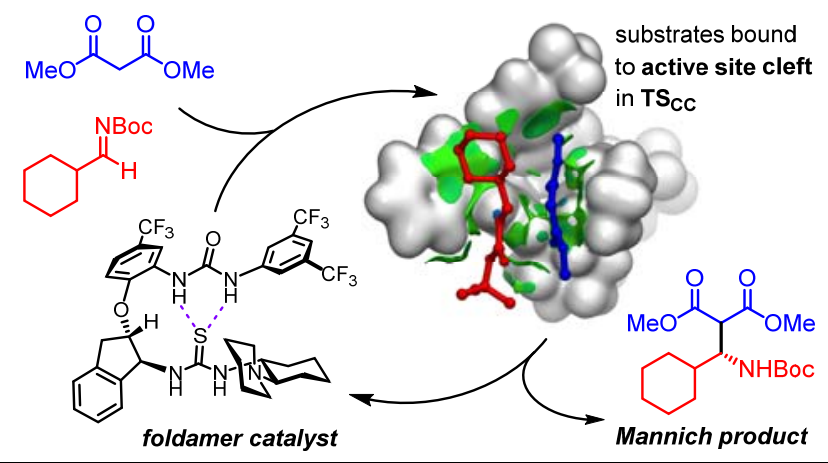

